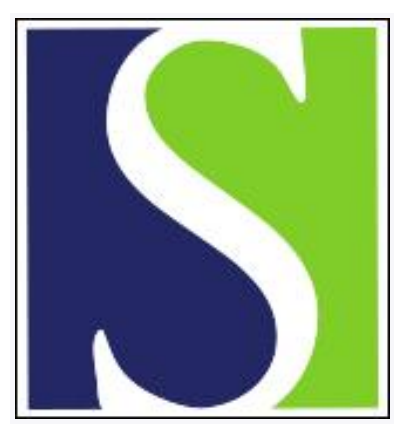

Scand J Work Environ Health 1995;21(4):277-282

https://doi.org/10.5271/sjweh.38

Issue date: Aug 1995

Perinatal outcome among the offspring of employees and people living around a Swedish smelter

by Wulff M, Högberg U, Sandström AIM

Key terms: birthweight; occupational exposure; perinatal death; pregnancy outcome; smelter work

This article in PubMed: www.ncbi.nlm.nih.gov/pubmed/8553002

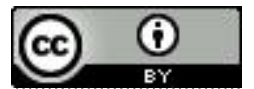




\title{
Perinatal outcome among the offspring of employees and people living around a Swedish smelter
}

\author{
by Marianne Wulff, MD, ${ }^{1}$ Ulf Högberg MD, PhD, ${ }^{1}$ Anita IM Sandström, $P h D^{2}$
}

\begin{abstract}
Wulff M, Högberg U, Sandström AIM. Perinatal outcome among the offspring of employees and people living around a Swedish smelter. Scand J Work Environ Health 1995;21:277-82.

Objective The purpose of this study was to determine if emissions from a smelter affect the birthweight of offspring and increase the risk of perinatal death.

Methods A historical cohort was formed from registers of birth and employees from 1961 to 1991. Comparisons of birthweight and perinatal deaths between children born to smelter employees or children born to women living around the smelter and those of a reference population were performed. To study reproductive effects before 1961, a case-referent study was performed with cases of stillbirths from 1937-1961 in one parish

Results No differences in birthweight were found between the children born to employees or to people living near the smelter and those in the reference group. An increased risk of perinatal death among children born to women in the exposed group was seen during the period 1966-1970. However, for the rest of the observation period, 1961-1990, this higher risk was not apparent.

Conclusions For the last 20 years emissions from the smelter had not affected the birthweight and the risk of perinatal death among the offspring of parents living near the smelter or those employed at the smelter.
\end{abstract}

Key terms birthweight, occupational exposure, perinatal death, pregnancy outcome, smelter work.

The results presented in this report come from a broad study of reproductive outcome among smelter workers and people living around a smelter in Sweden.

With more women becoming employed, growing interest regarding the possible hazards related to occupational exposure has arisen. Now, more often than before questions arise about a possible connection between a woman's job and her experience of spontaneous abortion, the delivery of a malformed child, or a stillbirth. Human reproduction is a complex process with a potential for several adverse effects, such as menstrual cycle dysfunction, reduced fecundity (reduced ability to conceive), infertility, poor semen quality, spontaneous abortion, stillbirth, preterm delivery, low birthweight, congenital malformations, childhood cancer, and neurological disorders in childhood (1). The most significant threats are biological, but even environmental and occupational hazards play an important role (2-5). The extent to which occupational factors affect reproduction is unknown. Reviews of the literature on the subject indicate methodological problems such as difficulties in determining the degree of exposure and problems with study design (appropriate comparison group, bias), anal- yses and interpretation of the results (1). Only a few proved toxicants have been found, but nevertheless agents associated with adverse reproductive outcome in the workplace occur in many groups, for example, heavy metals, ionizing radiation, organic solvents, polychlorinated biphenyls $(\mathrm{PCB})$, sterilizing agents (ethylene oxide), gases (carbon monoxide, anesthetic gases), plastics, heat, cold, and noise (6-9).

In the United States the following four workplace exposures have been regulated on the basis of reproductive effects: ionizing radiation, lead, dibromochloropropane (DBCP), and ethylene oxide (1). In Sweden pregnant women are not allowed in workplaces using lead, ionizing radiation, or diving. In addition to these forbidden areas the Swedish Board for Occupational Safety and Health regulates work with biological agents, chemical agents, noise, vibration, temperature, and mental strain $(10,11)$.

The Rönnskär smelter is a copper smelter situated in the province of Västerbotten, in the north of Sweden (figure 1). Production started in 1930. Ore containing copper, silver, gold, lead, and arsenic is melted in the furnace, which emits sulfur dioxide and heavy metals,

1 Department of Obstetrics and Gynaecology, University of Umeå, Umeå, Sweden.

2 Department of Epidemiology and Public Health, University of Umeå, Umeå, Sweden.

Reprint requests to: Dr M Wulff, Department of Obstetrics and Gynaecology, University Hospital, S-901 85 Umeå, Sweden. 


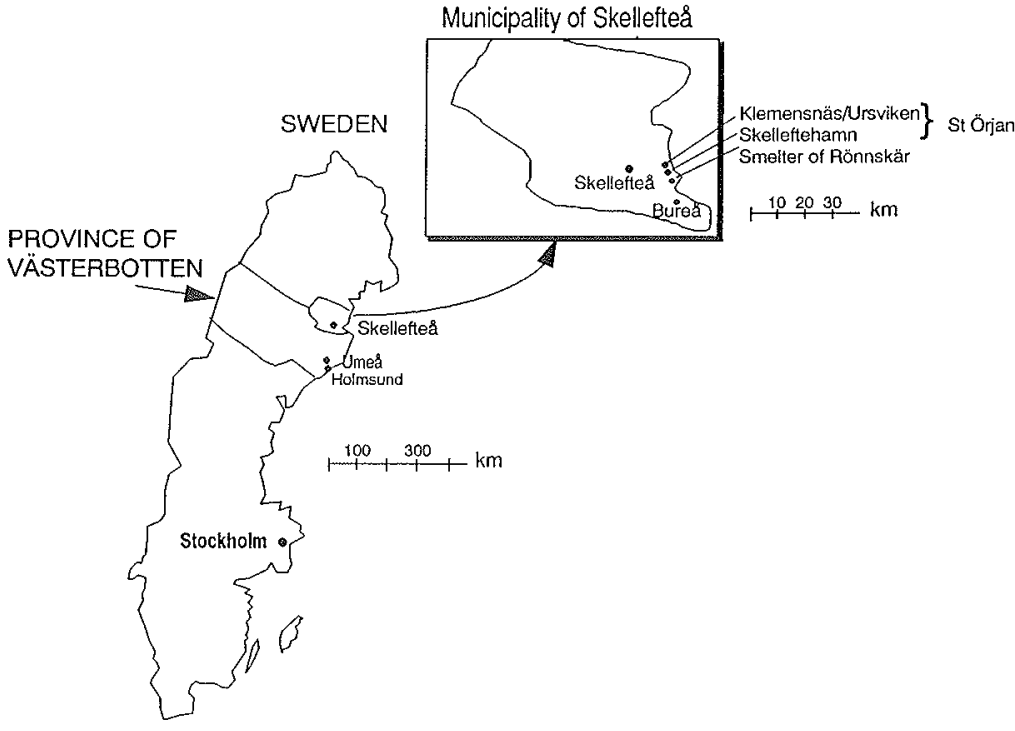

Figure 1. The municipality of Skelleftea with the neighboring area of St Örjan and Bureå. including lead, copper, zinc, cadmium, mercury, and arsenic, into the surrounding countryside. The release of all heavy-metal pollutants in the air and water has been radically reduced over the last 15 years. The emission of lead, copper, and mercury to the air has diminished from 200 to $52 \mathrm{t}$ a year, from 190 to $18 \mathrm{t}$ a year and from 1 to

\section{STUDY DESIGN}

\section{The cohort study}

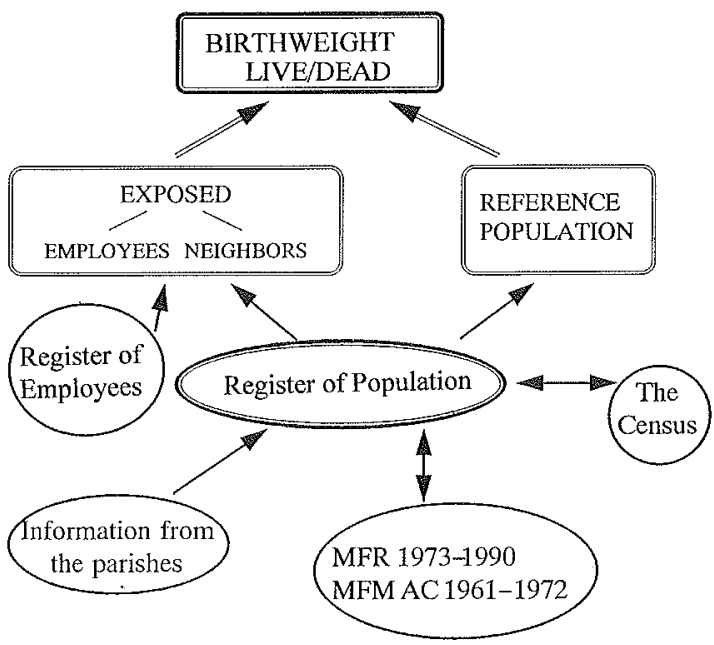

\section{The case-referent study}

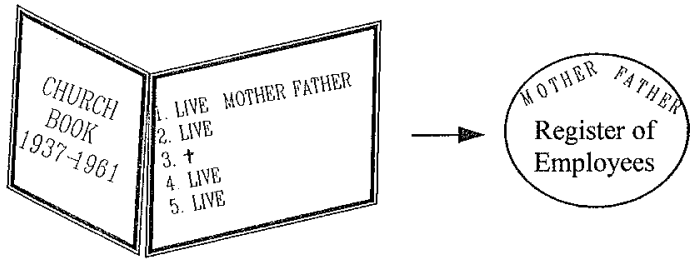

Figure 2. Study design.
$0.25 \mathrm{t}$ a year, respectively. The emission of arsenic to water has diminished from 1200 to $8 \mathrm{t}$ a year. Compared with the background levels, the concentrations of lead, zinc, and cadmium were still elevated within a radius of $30 \mathrm{~km}$ from the smelter, and elevated concentrations of copper and arsenic could be found within a radius of $40 \mathrm{~km}$ (12). Different occupational hazards, in particular lung diseases, have been described at the smelter. An excess incidence of cancer has been found among the workers at the smelter, but it appears to be declining (13). During the late 1970 s studies demonstrated an increased rate of spontaneous abortion and a lower birthweight for children of employees, as well as for children born to women living close to the smelter. In addition, the number of congenital malformations was increased among children born to mothers who worked at the smelter during pregnancy (14-15). Since the exposure of metals has been reduced considerably over the last 15 years, a follow-up of the reproductive outcome in this risk group is important. The aim of the study was to determine offspring birthweight and the number of perinatal deaths for a population living around the smelter and for parents working at the smelter and compare these values with those of a reference population (figure 1).

\section{Material and methods}

Two studies were designed (figure 2) to compare different incidence rates between the exposed and unexposed groups: a retrospective cohort study (follow-up study) and a case-referent study. Retrospective cohort studies, which are common in occupational epidemiology, are based on information about exposure and disease collected in the past, often using different registers as 
sources. In our cohort study we compared birthweight and perinatal deaths between exposed and unexposed groups covering the period 1961-1990. Data on these end points of reproduction were not available before 1961. Because of our interest in the reproductive outcome before 1961, we performed a case-referent study using the registers of births in the parish of St Örjan from 1937 until 1961 by registering all stillbirths as cases (figure 2).

\section{Retrospective cohort study}

The cohort consisted of 30644 children born between 1961 and 1990. Within the cohort, it was possible to define the following five categories according to the exposure gradient: (i) children born to mothers employed as blue-collar workers, (ii) children born to fathers employed as blue-collar workers, (iii) children with a parent employed as a salaried employee, (iv) children born in the neighborhood (St Örjan and Bureå, within $20 \mathrm{~km}$ of the smelter), and (v) children belonging to the reference population, the unexposed group. The exposed group was defined as children born to at least one parent working at the smelter and children born to parents in the neighborhood. Thus the exposed group included children belonging to the first four categories, which totaled 4400 children. These children were all born in the parish of St Örjan. The reference population consisted of children born in all other parishes of the municipality of Skellefteå and children in the parish of Holmsund (figure 1), a total of 26244 .

The basic information about the cohort was obtained from the Register of Population, Statistics Sweden, which receives information about births and perinatal deaths from the parishes. This register includes an identification of the mother and also of the father if the parents were married at the time the child was born. For those parents who were not married, further identification of the father was made by linking this register to the Census Register (Folk- och Bostadsräkningarna) for 1960, 1965, 1970, 1975, 1980, and 1985.

Information regarding employment at the smelter, as either a blue-collar worker or a salaried employee, was obtained by linkage to the Register of Employees at the smelter for 1961 until 1990. Employment for at least three months within the last 12 months was required of the mother. Regarding the father a preconceptional period of at least three months was required. Women working at the smelter were mostly employed as cleaners, laboratory workers, clerks, or canteen personnel. Additional information about the children was obtained from the Birth Register of Västerbotten Province 1961-1972 (MFM AC 1961-1972) and the Medical Birth Register
1973-1990 (MFR 1973-1990), which was managed and funded by the National Board of Health and Welfare. Birthweights were accessible from 1973 on and were registered to the nearest $10 \mathrm{~g}$. This register also contains certain information on socioeconomic factors, maternal smoking during the first trimester, contraceptive usage, maternal diseases, and complications during pregnancy, delivery or during the neonatal period. A condition for the multilinkage of our register was the identification of the child, mother, and father by the personal identification numbers (ie, the official Swedish identification numbers) a 10-digit number unique to all persons living in Sweden. By approval of the Swedish Authority of Computer Security this linkage was performed by Statistics Sweden. Therefore neither the identity of the child, the mother, or the farther was known to the researchers.

\section{Case-referent study}

In order to study the reproduction at the smelter before 1961, although no computer data were available, we were able to use the church records from the parish of Skelleftehamn, where the smelter is situated. We performed a case-referent study by registering all of the stillbirths from 1937 until 1961 as cases (before 1961 Skelleftehamn was a separate parish, after 1961 Skelleftehamn and Klemesnäs/Ursviken were united as the parish of St Örjan). When a stillborn child was observed in the records, it was registered as a case. As referents to this case we registered four children born live, the two born just prior to and the two born just after our case as recorded in the church records. Having identified our cases and referents, we looked further into the church records and identified the parents of these children. We then linked the personal identification numbers of the parents to the Register of Employees to see if more stillbirths could be found among the offspring of the smelter workers (figure 2). Only the crude odds ratios were calculated. All of the confidence limits were $95 \%$ limits.

\section{Results}

The cohort consisted of 30644 children born in the period 1961 - 1990. Data on birthweights were available from 1973 on, and we found 17567 children with a birthweight recorded in this period, 2666 belonging to the exposed group and 14901 belonging in the unexposed group.

Perinatal mortality, defined as stillbirth or death within $7 \mathrm{~d}$ of delivery, could be calculated during the whole 


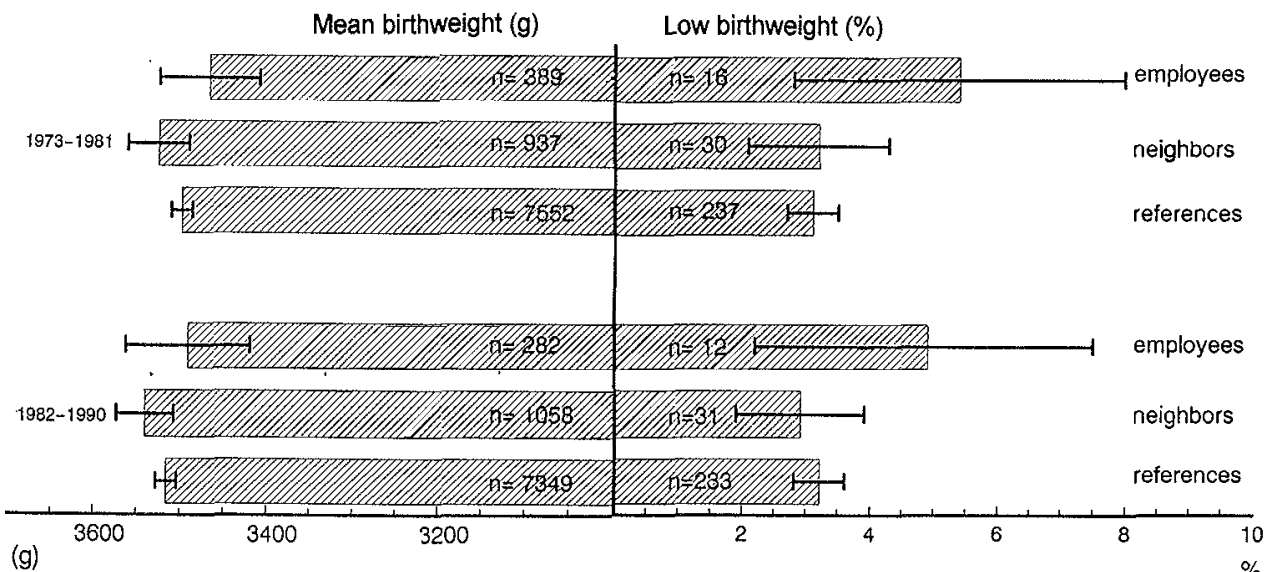

Figure 3. Birthweight (grams) and low birthweight (percentages), with the $95 \%$ confidence intervals, according to exposure gradient for singleton births was also shown.

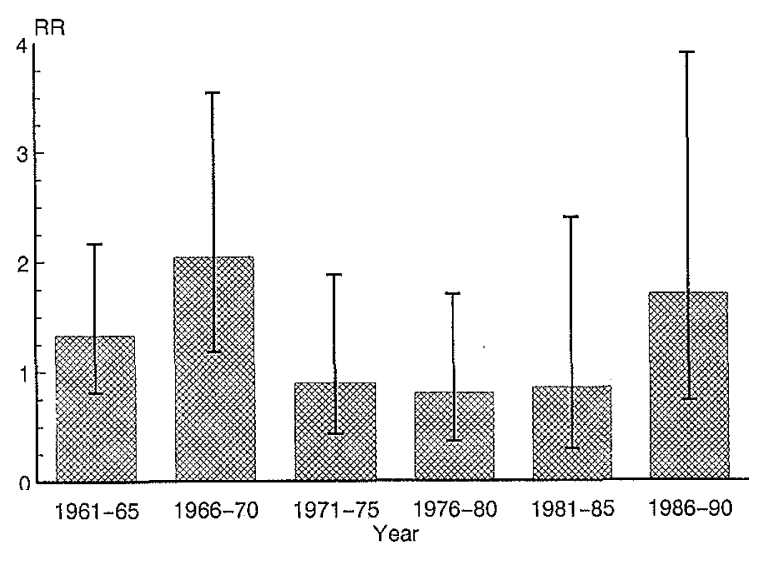

Figure 4. Risk of perinatal death in the exposed group compared with a reference group, presented as the odds ratios and $95 \%$ confidence intervals for five-year intervals.

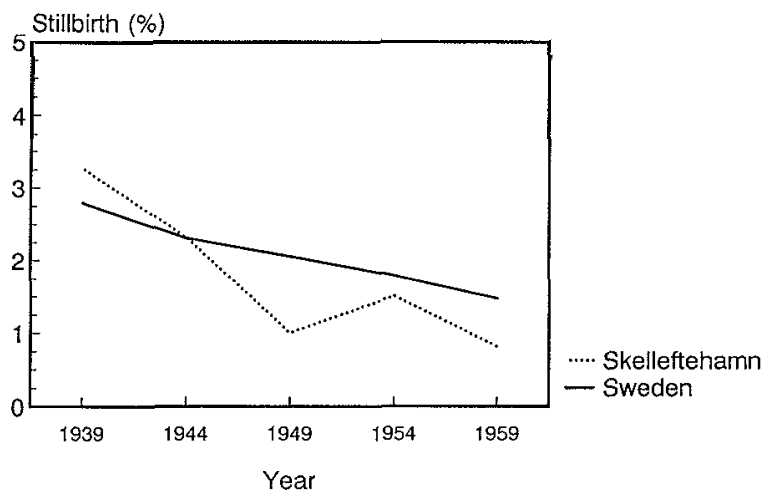

Figure 5. Percentage of stillbirths in Skelleftehamn and in Sweden as a whole in five-year mean values. (Source: Vital Statistics 1983-1961, Statistics Sweden)

period, 1961-1990.

Data on smoking habits during pregnancy were available from 1982 on.
The mother's age, parity, and smoking were considered possible confounders. Age and parity did not differ among the exposed and unexposed categories. The percentage of smoking in the two groups differed only somewhat (24 versus $21 \%$ ), but within the exposed group $37 \%$ of the pregnant female blue-collar workers were smokers.

During the period 1973-1981 the mean birthweights of children born to employees, to parents living close to the smelter, and to those in the reference area were 3467 , 3525 and $3499 \mathrm{~g}$, respectively. For the period 19821990 the figures were 3491,3541 , and $3516 \mathrm{~g}$, respectively. As figure 3 shows, no statistically significant differences were found for the mean birthweights between the different exposure groups (figure 3 ).

Data on smoking habits were available in the register from 1982 on. Adjustment for smoking habits did not affect the mean birthweight in any group.

Low birthweight was defined as a birthweight of less than $2500 \mathrm{~g}$. There was no difference between the frequencies of low birthweight in the neighbor and reference groups, but in both calendar periods we found a difference between the employees and the referents, although the difference was not significant.

The data base contained information on perinatal deaths for all 30 years, $1961-1990$. We found 62 perinatal deaths out of 4400 births among the exposed smelter employees and those living in the neighborhood, and there were 300 perinatal deaths out of 26244 births among the women living in the reference area. For the period 1966-1970 we found an excess risk of 2.04 for the exposed persons (95\% CI 1.18-3.54). During the rest of the period this higher risk was not apparent (figure 4).

Before analyzing the data for the case-referent study, we looked at the number of stillbirths in Skelleftehamn compared with that of Sweden and found no differences (figure 5). 
In our study we found 37 stillbirths in Skelleftehamn during the period 1937-1961. The references were children born live and matched for place and date of birth as described in the Material and Methods section. Thus we found 138 approved referents.

When calculating the crude odds ratios, we found no association between the number of stillbirths and parents working at the smelter (table 1).

\section{Discussion}

Looking at the quality of our data, we would suspect few missing cases, as the Medical Birth Register covers more than $99 \%$ of all births in Sweden. Every year the Register of Population and the Medical Birth Register are compared regarding births and deaths according to the mothers' personal identification number. A quality study of the Swedish birth register showed that "hard" data such as perinatal survival and birthweight distributions are reliable parameters to be evaluated (18). Birthweight was available from 1973 on, and the exact numbers of cases without a birthweight in our study was 115 singletons, $0.7 \%$. There was no missing information on the variable liveborn-stillbirth or dead within $7 \mathrm{~d}$. Data on smoking was available from 1982 on and was missing for $12 \%$ of the women studied. When looking at the different categories, we found smoking data missing for $16 \%$ of the employees, $14 \%$ of the neighbors, and $12 \%$ of the reference population.

We must consider how far is it possible to address our hypothesis by the study design with a rather small sample size in relation to the measured outcome variables, regarding, for example, the risk of perinatal death. With the given sample size and a power of $80 \%$, a relative risk of 1.5 could be detected for the whole study period. This finding illustrates the difficulties of epidemiologic evaluations of reproductive risks. For the period 1966-1970 we found an increased number of perinatal deaths among children born to women in the exposed group when compared with the reference population. Furthermore, a tendency towards an elevated risk was seen in the period 1961-1965. One interpretation of this time trend could be that, during the 1960 s, environmental exposure caused more perinatal deaths. When looking at the birthweights, and especially the low birthweights, we found a tendency towards an increased risk for children born to smelter employees, although it was not significant. Any interpretation of our results should be cautious, but the tendencies could be important and the reason for the nonsignificant differences may be the small sample size and therefore the wide confidence intervals.

For the case-referent study the cases were very few, but for this period, 1937-1961, we used the only repro-
Table 1. Stillbirth among the children born to the smelter employees (exposed) and nonsmelter employees (unexposed) 1937-1961. (OR = odds ratio, $95 \% \mathrm{Cl}=95 \%$ confidence interval)

\begin{tabular}{lcccc}
\hline Group & Cases & Referents & OR & $95 \% \mathrm{Cl}$ \\
\hline Unexposed & 26 & 62 & 1 & - \\
Exposed & 11 & 76 & 0.35 & $0.16-0.74$ \\
\hline Total & 37 & 138 &. & \\
\hline
\end{tabular}

ductive parameter available.

As possible confounders the age of the mother, parity, and smoking were considered. Age and parity did not differ in the exposed and unexposed groups. Higher percentages of children with a low birthweight were found among the smoking pregnant women however.

The potentially reproductive toxic agents used at the smelter were lead, mercury, arsenic, copper, zinc, gold, silver, cadmium, and sulfur dioxide. These agents were also found in the surroundings, in the water, air and soil. Lead is a well-known reproductive toxicant associated with an increased rate of spontaneous abortion, malformations, effects on sperm quality (19), stillbirths (20, 21), and neurological disturbances $(22,23)$. A Danish study has shown that women exposed to lead, mercury, or cadmium might be at a higher risk of being infertile (24). Methyl mercury is associated with increased rates of stillbirth, spontaneous abortion, and defects in the central nervous system (25). Paternal exposure to mercury might result in increased rates of spontaneous abortion (26). An increased frequency of chromosome aberrations has been found among people exposed to inorganic arsenic $(27,28)$. Cadmium may induce a decrease in birthweight (29). Increased levels of copper and zinc in plasma have been associated with intrauterine growth retardation $(30-32)$.

In summary we did not find any adverse effects on mean birthweight or low birthweight for the neighbor group during the 1970 s or the $1980 \mathrm{~s}$. As for the group of employees, the population might be too small to detect differences.

During the period 1966-1970 there was an increased risk of perinatal death among the children born to the women in the exposed group, but no such increase was found during the last 20 years, a period in which emissions from the smelter had diminished considerably.

\section{Acknowledgments}

We thank Agneta Sträng-Abrahamsson, Statistics Sweden, for the data linkage, Göran Lindahl, UMDAC, for the data management, and Anita Nilsson and Lena 
Mustonen, Department of Epidemiology and Public Health, for their secretarial assistance.

The study was supported by grants from Boliden Mineral AB, the National Institute of Public Health, the Joint Committee North Health Region, and the Swedish Council for Social Research.

\section{References}

1. Hatch M, Marcus M. Occupational exposures and reproduction. In: Kiely M, editor. Reproductive and perinatal epidemiology. Boca Raton (FL): CRC Press, 1991:132-8.

2. Aberman E. Low birth weight. In: Bracken MB, editor. Perinatal epidemiology. New York (NY): Oxford University Press, 1984:86-99.

3. Kline J. Fetal growth and birthweight. In: Kline J, Stein Z, Susser M, editors. Conception to birth. New York (NY): Oxford University Press, 1989:208 - 40.

4. Källén B. Factors determining birthweight. In: Källén B, editor. Epidemiology of human reproduction. Boca Raton (FL): CRC Press, 1988:40-3.

5. Bakketeig LS, Hoffman HJ, Oakley AR. Perinatal mortality. In: Bracken MB, editor. Perinatal epidemiology. New York (NY): Oxford University Press, 1984:99-151.

6. Giacoia GP. Reproductive hazards in the workplace: review. Obstet Gynecol Surv 1992;47:679-87.

7. Strobino BR, Kline J, Stein Z. Chemical and physical exposures of parents: effects on human reproduction and offspring. Early Hum Dev 1978;1/4:371—99.

8. Rosenberg MJ, Feldblum PJ, Marshall EG. Occupational influences on reproduction: review of recent literature. J Occup Med 1987:584-91.

9. McDonald $\mathrm{AD}$. Work and pregnancy. $\mathrm{Br} \mathrm{J}$ Ind Med 1988:45:577-80.

10. The Swedish Board for Occupational Safety and Health. Limits of exposure. Stockholm: The Swedish Board for Occupational Safety and Health, 1993. Regulations no AFS 1993:9.

11. The Swedish Board for Occupational Safety and Health. Pregnant and wet nursing employees. Stockholm: The Swedish Board for Occupational Safety and Health, 1994. Regulations no AFS 1994:32.

12. Lundbergh $\mathrm{K}$. Deposition of heavy metals in the surroundings of the smelter of Rönnskär 1990. Skellefteå, (Sweden): Boliden Mineral AB, 1992.

13. Sandström A. Epidemiology at a smelter --changing patterns concerning lung cancer occurrence, work environment, smoking and risk perceptions over six decades [dissertation]. Umeå (Sweden): Umeå University, 1992. New series, no 353; ISSN 0346-6612.

14. Nordström S, Beckman L, Nordenson I. Occupational and environmental risks in and around a smelter in northern Sweden. Hereditas 1978;88:43-6.

15. Nordström S, Beckman L, Nordenson I. Occupational and environmental risks in and around a smelter in northern Sweden: frequencies of spontaneous abortion. Hereditas 1978; $88: 51-4$.
16. Nordström S, Beckman L, Nordenson I. Occupational and environmental risks in and around a smelter in northern Sweden: congenital malformations. Hereditas 1979;90:297-302.

17. Nordström S, Beckman L, Nordenson I. Occupational and environmental risks in and around a smelter in northern Sweden: spontaneous abortions among female employees and decreased birth weight in their offspring. Hereditas 1979;90: $291-6$.

18. Cnattingius S, Ericsson A, Gunnarskog J, Källén B. A quality study of a Medical Birth Registry. Scand J Soc Med 18;1990: $143-8$.

19. Rom N. Effects on lead on the female and reproduction, a review. Mt Sinai J Med (NY) 1976;43:542-52.

20. Khera AK, Wibberly DG, Dathan JG. Placental and stillbirth lead concentrations in occupationally exposed women. $\mathrm{Br} \mathrm{J}$ Ind Med 1980;37:394 - 6.

21. Bryce-Smith D, Deshpande RR, Hughes J. Lead and cadmium levels in stillbirths. Lancet 1977;1:1159.

22. Beattie AD, Moore MR, Goldberg A. Role of chronic lowlevel lead exposure in the aetiology of mental retardation. Lancet 1975:589-92.

23. Baghurst PA, McMichael AJ, Tong S, Wigg NR, Vimpani GV, Robertson EF. Exposure to environmental lead and visual-motor integration at age 7 years: the Port Pirie cohort study. Epidemiology 1995;6:104-9.

24. Rachootin $\mathbf{P}$, Olsen $\mathbf{J}$. The risk of infertility and delayed conception associated with exposures in the Danish workplace. J Occup Med 1983;25:394—402.

25. Levine RJ. Minamata disease. In: Working PJ, editor. Toxicology of the male and female reproductive systems. New York (NY): Hemisphere Publishing Corporation, 1989: $325-7$.

26. Cordier S, Deplan F, Mandereau L, Hemon D. Paternal exposure to mercury and spontaneous abortions. $\mathrm{Br} \mathrm{J}$ Ind Med $1991 ; 48: 375-81$.

27. Petres J, Baron D, Hagendorn M. Effects of arsenic cell metabolism and cell proliferation. Environ Health Perspect 1977; 19:223.

28. Nordenson I, Beckman G, Beckman L, Nordström S. Occupational and environmental risks in and around a smelter in Northern Sweden: cromosomal aberrations in workers exposed to arsenic. Hereditas 1978;88:47-50.

29. Frery N, Nessman C, Girad F, Lafond J, Moreau T, Blot P, et al. Environmental exposure to cadmium and human birth weight. Toxicology 1993;79:109-18.

30. Borella P, Szilagyi A, Than G, Csaba I, Giadino A, Facchinetti F. Maternal plasma concentrations of magnesium, calcium, zinc and copper in normal and pathological pregnancies. Sci Total Environ 1990;99:67- 76 .

31. Bro S, Berendtsen $H$, Nörgaard J, Höst A, Jörgensen PJ. Serum zinc and copper concentrations in maternal and umbilical cord blood: relation to course and outcome of pregnancy. Scand J Clin Lab Invest 1988:48:805-11.

32. Soo TL, Simmer K, Carlson L, McDonald L. Copper and very low birth weight infants. Arch Dis Child 1988;63:79—81.

Received for publication: 2 March 1994 